This paper has not been peer reviewed. Please do not copy or cite without author's permission

\author{
What does (and should) "mind wandering" mean? \\ Paul Seli ${ }^{1 *}$, David Maillet ${ }^{1}$, Daniel L. Schacter ${ }^{1}$, Michael J. Kane ${ }^{2}$, \\ Jonathan Smallwood ${ }^{3}$, Jonathan W. Schooler ${ }^{4}$, and Daniel Smilek ${ }^{5}$ \\ ${ }^{1}$ Department of Psychology and Center for Brain Science, Harvard University, Cambridge, MA, USA \\ ${ }^{2}$ Department of Psychology, University of North Carolina Greensboro, NC, USA \\ ${ }^{3}$ Department of Psychology, University of York, York, UK \\ ${ }^{4}$ Department of Psychology, University of California Santa Barbara, Santa Barbara, CA, USA \\ ${ }^{5}$ Department of Psychology, University of Waterloo, Waterloo, ON, Canada
}

\begin{abstract}
Author Note
This research was supported by a Natural Sciences and Engineering Research Council of Canada (NSERC) discovery grant to Daniel Smilek (grant number 06459), an NSERC Post-Doctoral Fellowship to Paul Seli, and a Fonds de Recherche Santé Québec - Réseau Québécois de recherche sur le vieillissement (FRSQ-RQRV) postdoctoral training award to David Maillet. Correspondence may be directed to Paul Seli, Department of Psychology, Harvard University, William James Hall, 33 Kirkland Street, Cambridge, MA, 02138. Email: paulseli@fas.harvard.edu.
\end{abstract}




\begin{abstract}
In recent years, there has been a tremendous increase in the number of studies examining mind wandering, and research on the topic has spread widely across various domains of psychological research. As research on the topic of mind wandering has accelerated, the defining features of this conscious state have expanded, and researchers have begun to define mind wandering in conceptually and operationally different ways between - and sometimes even within - studies. Yet, despite clear differences in the definitions adopted, 'mind wandering' is often discussed in broad terms, and inferences drawn by researchers are rarely constrained to their specific operational definitions. This practice produces a lack of clarity in our understanding of mind wandering, and it can lead to illusory inconsistencies in the literature. To minimize these problems, we propose that researchers adopt a family-resemblances approach to the investigation of mind wandering, which entails (a) treating mind wandering as a heterogeneous construct and (b) more clearly measuring and describing the specific aspects of the variety of mind wandering that researchers are attempting to investigate. To help move the field forward, we delineate a prototypical case of mind wandering in the broader context of related forms of thought, which should guide the use of the term in future research.
\end{abstract}

Keywords: mind wandering; definition; heterogeneous; prototype; family resemblances 
The less a science has advanced, the more its terminology tends to rest on an uncritical assumption of mutual understanding. (Quine, 1936, p. 90)

It would do violence to the language, and is undoubtedly unattainable in practice, to narrow the allowable denotative meanings of "daydreaming" or "fantasy" to one of the underlying dimensions. (Klinger \& Cox, 1987-88, pp. 124-125)

\section{What does (and should) "mind wandering" mean?}

Over the past decade, psychological science has come to appreciate the importance of a mental state that, prior to that time, everyone experienced but relatively few explicitly studied: the mind's tendency to engage in rich thought that is unrelated to the here and now. Scientific investigation of this mental state, now commonly referred to as "mind wandering," has burgeoned. As illustrated in Figure 1, even as recently as 2005 and 2006, there was a dearth of research examining mind wandering, whereas in more recent years, there has been an enormous increase in such investigations, with 111 papers on the topic published in 2016.

------------Please insert Figure 1 here------------

What happened to make mind wandering such a popular topic? Several important research developments likely contributed, but we speculate that a change in nomenclature from a variety of unfamiliar esoteric terms (e.g. stimulus-independent thought, task-unrelated thought, fantasy proneness) to a single familiar term (mind wandering) may have played a significant role. While the consolidation of allusions to this familiar mental state may have furthered its widespread 
scientific investigation, it also contributed to an increasingly vexing challenge: Numerous related but non-identical phenomena have all been lumped together under the single rubric of "mind wandering."

In this article, we first consider briefly the factors that led to the increased investigation of mind wandering. We then discuss how convergence on the term "mind wandering" has led to potential confusions in the literature on the topic. We argue that our understanding of mind wandering will be improved by: (a) adopting a framework that accounts for the rich and varied nature of the mind-wandering experience, and (b) focusing on the presentation and interpretation of experimental results in terms of the specific variety (or varieties) of mind wandering actually examined. We consider how definitions of mind wandering along a single dimension can be overly restrictive - because they often fail to capture aspects of experience that might reasonably be assumed to constitute a form of mind wandering — or overly inclusive — because they conflate aspects of the experience that are fundamentally different from mind wandering. Instead of adopting such definitions, we suggest that an effective approach will be to focus on mind wandering as a fuzzy category that includes a set of heterogeneous experiences that have many shared features, but also important differences, and we consider how these different experiences can be made the explicit focus of empirical investigations. Finally, we conclude with concrete suggestions for moving forward in the field of mind-wandering research (including the proposal of a prototype) in order to explicate mind wandering without confusing a set of interrelated phenomena whose importance has become increasingly evident. 


\section{Why has mind wandering become such a vigorously investigated topic of study?}

It is difficult to determine how researchers choose particular lines of investigation.

Nevertheless, we speculate that several factors may have inspired researchers to investigate mind wandering.

The ubiquity of the phenomenon: With the advent of experience-sampling methodologies (for reviews, see Csikszentmihalyi \& Larson, 1987; de Vries, Dijkman-Caes, \& Delespaul, 1990; Hulburt, 1997) that allow researchers to sample the occurrence of mental events in everyday life, it has become increasingly apparent that people spend a large portion of their waking lives engaging in mind wandering. Several studies (e.g., Kane et al., 2007; Killingsworth \& Gilbert, 2010; Song \& Wang, 2012) suggest that people spend 25-50\% of their waking hours mind wandering. A growing appreciation of the ubiquity of mind wandering likely spurred its accelerating investigation.

The validation of self-reports of mind wandering: One likely reason why many researchers initially shied away from investigating the phenomenon is that it is a private mental state whose measurement relies on self-report measures that are often viewed with skepticism. However, accumulating evidence has documented the validity of mind-wandering reports by demonstrating their convergence with a host of other indirect measures. These include behavioral measures, such as performance errors (e.g., McVay \& Kane, 2009), comprehension failures (e.g., Schooler, Reichle, \& Halpern, 2004), eye movements (e.g., Uzzaman \& Joordens, 2011), and response variability (e.g., Seli, Cheyne, \& Smilek, 2013), as well as physiological measures, such as evoked response potentials (e.g., Smallwood, Beach, Schooler, \& Handy, 2008), pupil dilation (e.g., Franklin, Broadway, Mrazek, Smallwood, \& Schooler, 2013), eye blink rate (e.g., Smilek, Carriere, \& Cheyne, 2010), and changes in brain activity (e.g., Christoff, Gordon, 
Smallwood, Smith, \& Schooler, 2009). Although researchers have recently begun to investigate situations in which self-reports of mind wandering may be more versus less accurate (e.g., Seli, Jonker, Cheyne, Cortes, \& Smilek, 2015), these behavioral and physiological findings have bolstered researchers' confidence in self-reports.

The costs of mind wandering: Research has increasingly illuminated ways in which mind wandering can disrupt ongoing-task performance. It is a major source of comprehension failure during both reading (e.g., Unsworth \& McMillan, 2013) and lectures (e.g., Jing, Szpunar, \& Schacter, 2016; Szpunar, Khan, \& Schacter, 2013). Mind wandering also contributes to failures in sustained attention (e.g., Seli, 2016), working memory (e.g., McVay \& Kane, 2009), and general intelligence tests (Mrazek et al., 2012), and impairs driving performance (e.g., Yanko \& Spalek, 2013a, 2013b), rivalling alcohol intoxication and texting as a source of automobile accidents. Mind wandering has also been implicated in performance variations in pilots (Casner \& Schooler, 2013). Clearly, a phenomenon that has such potentially broad and serious consequences deserves thoughtful investigation.

The benefits of mind wandering: The fact that people mind-wander so often, despite its evident costs, suggests that its experience might also have value. Limited empirical research suggests the benefits of mind wandering may include enhanced creativity (e.g., Baird et al., 2012; but see Smeekens \& Kane, 2016), opportunity for planning (e.g., Rummel, Smeekens, \& Kane, in press; Stawarczyk, Majerus, Maj, Van Der Linden, \& D’Argembeau, 2011), attenuation of habituation (Mooneyham \& Schooler, 2016), and relief from boredom (Baird, Smallwood, \& Schooler, 2010). This potential value of mind wandering has captured the imagination of both researchers (for a review, see Mooneyham \& Schooler, 2013) and the media (e.g., Gargiulo, 2013; Sapolsky, 2015; Tierney, 2010). 
The default network: Coincidentally, as mind wandering investigations were increasing, researchers were independently discovering a network in the brain (the "default mode" network; Raichle, 2015) that becomes increasingly active when participants are not engaged in a designated "task" (i.e., when they are "at rest"). It has become increasingly clear that this network's activity reflects spontaneous internal cognitions (see Buckner, Andrews-Hanna, \& Schacter, 2008). Further research has indicated that this network is similarly active when individuals are mind wandering while engaged in task (e.g., Christoff et al., 2009). This increasingly appreciated brain network has helped accelerate research on mind wandering, as both can be viewed as characterizing the default state of the human brain.

The term "mind-wandering": Up until 2006, states that subsequently would likely have been referred to as mind wandering were characterized in the psychological literature by a host of obscure and unfamiliar names (e.g., task-unrelated thought; stimulus-independent thought). In a widely-cited review of the literature, however, Smallwood and Schooler (2006) argued for the value of the nomenclature of "mind wandering" as the umbrella term to describe the phenomenon, noting:

Perhaps part of the reason why mind wandering has escaped mainstream attention is that research addressing the issue has been framed in the context of a variety of disparate constructs... These various lines of research have all addressed the basic phenomenal characteristics of mind wandering, a shift of attention away from a primary task towards internal information, such as memories.... by referring to this phenomenon as mind wandering, a term familiar to the lay person, we hope to elevate the status of this research into mainstream psychological thinking (Smallwood \& Schooler, 2006, p. 946). 
As can be seen in Figure 1, following this review and its advocation of the use of term "mind wandering," the field witnessed dramatic increases in both research on this general topic and the specific favoring of the moniker of "mind wandering" over other terms.

\section{Challenges to the use of mind wandering as an all-inclusive term}

Although the field appears to have been stimulated by the convergence of disparate research traditions under the rubric of mind wandering, this may not have been without some costs. One such cost becomes evident when considering the challenges of experimentally operationalizing the concept of mind wandering — a step that is necessary when assessing mind wandering in laboratory settings and in daily life, and which is essential for theoretical progress. Due to differences in research traditions and research questions, these conceptualizations and operationalizations have shown substantial variation across studies, yet as noted, it has become common practice for researchers to discuss results in terms of a "generic" conception of "mind wandering." We argue that there are situations in which it may be problematic to conflate different empirical results because the studies and their interpretations were based on disparate operational definitions of mind wandering. Grouping various empirical results may obscure important details (and distinctions) and thereby hinder the emergence of a mature scientific account of mind wandering that is sensitive to the complex and often heterogeneous nature of the experience.

Although recent investigations have generally neglected the idea that mind wandering is a family of related experiences, this view was explored several decades ago. Klinger and his colleagues (e.g., Klinger, 1978-79; Klinger \& Cox, 1987-88) assessed and defined “fantasy,” or "daydreaming," along three orthogonal dimensions of thought: (a) involuntary-undirected- 
respondent thought versus voluntary-directed-operant thought, (b) fanciful-bizarre versus realistic thought, and (c) stimulus-independent versus stimulus-dependent thought (for a more recent multidimensional approach in the context of neuroimaging, see Smallwood et al., 2016; for a multidimensional approach to the study of daydreaming-related habits or traits, see Singer \& Antrobus, 1963). As detailed below, we believe it is now time to reinstate the practice of embracing the rich complexity of the phenomena that we are investigating.

\section{Definitional Complications in the Mind-Wandering Literature}

\section{Mind wandering as an experience unrelated to a focal task}

The most common approach that researchers have taken is to operationalize the experience of mind wandering as thought content and cognitive processing that is removed, in varying degrees, from some ongoing, externally oriented task (e.g., Smallwood \& Schooler, 2006). ${ }^{1}$ But should task relevance constitute the exclusive dimension along which to define mind wandering? On the one hand, this definition takes into account the fact that cognition varies depending on the features of a task or activity that is being performed. Studies of task-unrelated thought (TUT) can help identify the contexts that require participants to attend to the task they performing, which thereby allows researchers to draw conclusions about the underlying processes that support particular aspects of experience in a particular context, and those that support particular aspects of task performance (e.g., Giambra, 1989; Levinson, Smallwood, \& Davidson, 2012; McVay \&

\footnotetext{
${ }^{1}$ The scientific popularity and influence of the notion of task-unrelated thinking might reflect the fact that researchers typically measure the experience in a task context under laboratory conditions, thus providing a clear context to which the mind-wandering experience can be contrasted. Or, it might instead reflect a deeper shared theoretical commitment to a conceptualization of mind wandering as an inability to control cognition according to task or contextual demands.
} 
Kane, 2009; Seli, Cheyne, Xu, Purdon, \& Smilek, 2015). Moreover, such studies allow researchers to mimic the sorts of tasks that occur in daily life, which in turn allows them to understand the contribution that mind wandering plays in the "real world." This goal has been accomplished, for example, by examining mind wandering in the context of reading (e.g., Feng, D’Mello, Graesser, 2013; Unsworth \& McMillan, 2013), learning in classrooms (e.g., Wammes, Boucher, Seli, Cheyne, \& Smilek; Wammes, Seli, Cheyne, Boucher, \& Smilek, 2016), and driving (e.g., Yanko \& Spalek, 2013a, 2013b), all of which are tasks during which TUTs can have unhelpful consequences for the integrity of ongoing behaviour.

On the other hand, a disadvantage of defining mind wandering exclusively through its relation to tasks is that such a definition excludes many experiences that people would generally recognize as reflecting aspects of mind wandering. For example, we know from empirical investigations (Mason et al., 2007; Teasdale, Proctor, Lloyd, \& Baddeley, 1993) and from introspective evidence that our minds do not stop wandering when we are not performing a task (e.g., while sitting on a train). However, attempts to equate TUT with mind wandering have led researchers to awkwardly claim that mind wandering does not take place during taskindependent states. Consider a study by Baird et al. (2012), who examined performance on the Alternative Uses Task (AUT; Guilford, 1967) under several conditions imposed following participants" initial efforts to think of "unusual uses" for common objects, including: (a) performing a demanding task, (b) performing a less-demanding task, (c) having a period of rest, or (d) performing an immediate repetition of the AUT with no intermediate activity. The authors hypothesized that the less-demanding task would produce more mind wandering than the demanding task and that this less constrained thinking would lead to improved performance on the AUT (interpreted as indicating greater creativity). Consistent with their hypothesis, the less- 
demanding task elicited more mind wandering than did the demanding task and, critically, the less-demanding task also yielded more subsequent novel uses relative to the demanding task (but see Hao, Wu, Runco, \& Pina, 2015; Smeekens \& Kane, 2016). The authors were somewhat more challenged, however, in considering how "mind wandering" pertained to the rest condition, because the authors had initially equated TUT with mind wandering:

The score on the retrospective mind-wandering scale in the rest condition $(M=2.35$, $S D=0.57)$ was not significantly different from the score on this scale in either the undemanding-task condition $(p=.44)$ or the demanding-task condition $(p=.19)$, although this comparison is difficult to interpret because the rest condition included no primary task to which internal thoughts could fail to pertain (Baird et al., 2012; p. 1121; italics added).

Thus, a definition of mind wandering requiring a task context (i.e., TUT) precluded a coherent measure of mind wandering during the rest condition. Note that, by the authors' formal definition, mind wandering could not occur during a rest period because this condition did not include a primary task, yet the authors collected retrospective reports of mind wandering during the rest condition (and participants willingly provided them). Thus, here we have the anomalous situation of having participants provide retrospective reports on mental events that could not, by formal definition, have occurred in that context (for a similar example from a neuroimaging context, see McKiernan et al. 2006). This apparent paradox presumably resulted from entertaining two conceptions of mind wandering: (a) an explicit formal definition (i.e., "TUT"), and (b) an implicit understanding based on everyday experience (i.e., that our thoughts may 
wander even when we are not attempting to perform a nominal task).

At the same time, researchers have often assumed that measures of TUT generalize beyond the limited context of the task in which they were measured. For example, it is common for researchers to use the Imaginal Processes Inventory (IPI; Singer \& Antrobus, 1972) - a retrospective self-report questionnaire assessing "daydreaming" - as a proximal measure for TUT. Importantly, the daydreaming-related IPI questions (e.g., "Whenever I have time on my hands, I daydream," or "I lose myself in active daydreaming") do not require a focal task for "mind wandering" to be reported, so from the perspective of defining mind wandering in terms of TUT, it is unclear whether responses to the IPI reflect mind wandering, task-independent thoughts (which would not, according to a task-unrelated definition, qualify as mind wandering), or a combination of the two.

Another problem that arises when mind wandering is defined as TUT becomes evident when considering most studies that have examined mind wandering in daily life (e.g., Kane et al., 2007; Song \& Wang, 2012). Take, for example, the highly-cited article by Killingsworth and Gilbert (2010), in which the researchers assessed people's rates of mind wandering as they went about their daily routines. To measure mind wandering, the researchers developed a web application for participants' smartphones, which queried participants at random points during their daily activities. Although participants responded to numerous questions via their smartphones at each occasion, of primary interest here is the question the researchers administered to assess participants' rates of mind wandering: "Are you thinking about anything other than what you're currently doing?" (Killingsworth \& Gilbert, p. 932). In cases where a "yes" response was provided, the authors categorized such a response as "mind wandering," whereas in cases where a "no" response was provided, this response was taken to indicate a lack 
of mind wandering. Importantly, although the researchers did not explicitly define mind wandering as TUT in their article, the wording of their mind-wandering probe suggests an implicit assumption that, in order for people's minds to wander, they must be "doing something" (presumably a "task") away from which their minds can wander. Thus, the authors' assumption appears to have been that their participants were always engaged in some sort of a task during their daily routines, and that thoughts about anything other than these tasks reflected mind wandering. One problem with this approach, however, is that we frequently find ourselves in situations where we are not completing a focal task, or engaging in any identifiable activity, but most of us would nevertheless agree that we often mind-wander in such situations. Another problem is that it is possible that, in some instances, participants' thoughts were internally focused and without guidance (a mental state that most of us would consider to be reflective of mind wandering), but they nevertheless had awareness of their thoughts (Schooler, 2002). In such a case, participants would, by most accounts, be engaged in mind wandering, but when presented the question "Are you thinking about anything other than what you're currently doing," their response would presumably be "no," (given that they were thinking/aware of their unguided thoughts). In such cases, then, what was arguably a state of mind wandering would have been categorized as a state of focused thought.

Even if one were to concede that mind wandering is best conceptualized as TUT, this perspective would suggest that a more appropriate method of assessing rates of "mind wandering" in daily-life studies would be to ask participants whether they were completing a task that they eventually neglected in the service of mind wandering. Of course, by the TUT definition of mind wandering, if participants were to report that they were not completing a focal task, mind wandering could not, by definition, have occurred. However, in Killingsworth and 
Gilbert (2010), participants were provided no such option. Thus, the estimated rates of daily-life mind wandering obtained in this study would seem problematic for any proponent of a TUT definition of mind wandering, insofar as these rates of mind wandering include cases in which people were mind wandering in the absence of a focal task (which is clearly inconsistent with a TUT-based definition). Thus, here again we encounter a situation in which there is an apparent discrepancy between researchers' definition of mind wandering (i.e., as TUT) and their implicit assumption that mind wandering can occur even in task-free contexts.

Another problem with defining mind wandering with respect to a "task" is that, in many situations, it is not clear what constitutes a "task." However, the essentials of a task, as the term seems to be most often used, would appear to include an explicit commitment to guide one's attention toward performing (or refraining from performing) mental and/or behavioral actions entailing a goal, and, at least implicitly, a time frame in which performance should occur. Critically, from this perspective, primary tasks need not always be other-imposed: indeed, they can also, by this definition, be self-imposed. This is an important stipulation because it means that an individual can engage in a thought that is (a) unrelated to an externally imposed task (which, according to a TUT definition, would typically be classified as "mind wandering") but (b) focused on a self-selected and self-imposed task, which would therefore disqualify this thought as mind wandering. Take, for instance, the scenario in which a participant actively disregards as his ostensible "primary task" - the cognitive task assigned to him in the laboratory - and instead deliberately focuses his attention on a self-imposed primary task: For example, perhaps the participant actively produces a mental list of grocery items to purchase from the store. Critically, according to a TUT definition, such thoughts should not qualify as mind wandering (given that they are "on task" from the participants' perspective), even though in 
practice (and from the experimenter's perspective), such thoughts are routinely classified as mind wandering (for a similar view, see Metzinger, in press).

In light of the foregoing, it is clear that TUT is an unsatisfactory scientific definition of the mind-wandering state in its broadest sense, both in laboratory and in daily-life studies. Indeed, this definition excludes states that have intuitive relevance to a broader view of mind wandering (e.g., wakeful rest).

\section{The intentionality of mind wandering}

Another common defining feature of mind wandering that has emerged in the literature pertains to the extent to which the thought under investigation is engaged with or without intention. In particular, many researchers have defined mind wandering in terms of reflecting thoughts that occur in the absence of intention. Indeed, intentionally occurring thoughts might seem to best reflect states wherein people actively guide their attention toward a task, which appear to be antithetical to our general conceptualization of mind wandering. It is presumably the case that, for this reason, some researchers have explicitly defined mind wandering in terms of unintentional thought (e.g., Blanchard et al., 2014; Carciofo et al., 2014; Qu et al., 2015;

Rummel \& Boywitt, 2014; for more examples, see Seli, Risko, \& Smilek, 2016a, Supplemental Materials). One problem, however, with such a strict definition of mind wandering is that it excludes as cases of mind wandering situations in which people are at ease, sitting dreamily, allowing their thoughts to wander, or cases in which an individual deliberately neglects the task at hand in the service of entertaining TUT. Not only have many researchers considered such scenarios to reflect mind wandering (e.g., Golchert et al., 2017; Forster \& Lavie, 2009; Phillips, Mills, D’Mello, \& Risko, 2016; Seli, Risko, \& Smilek, 2016b; for a review, see Seli, Risko, Smilek, \& Schacter. 2016), but moreover, the viability of assuming that participants' reports of 
"mind wandering" uniformly lack intention has been brought into question by recent work that has shown that people often report engaging in "intentional mind wandering" in their daily lives (e.g., Seli, Risko, Purdon, \& Smilek, 2016; Seli, Smallwood, Cheyne, \& Smilek, 2015). Furthermore, in the laboratory, researchers have found that many of the TUTs that people report (which are often assumed to reflect unintentionally occurring thoughts) are in fact engaged intentionally (e.g., Seli, Cheyne, et al., 2015; Seli, Wammes, Risko, \& Smilek, 2015). Thus, although it may seem reasonable to define mind wandering in terms of unintentionally occurring thoughts, this definition suffers from the fact that it appears to be too exclusive of other thoughts that are commonly recognized as mind wandering.

At this point, it is worth noting that the terms "intentional" and "unintentional" mind wandering, as they have been used in research on mind wandering thus far, can be problematic because they can refer to different components of a mind-wandering episode, and the component to which they refer is not always clear (Seli, Ralph et al., in press). To understand why this is the case, it is useful to consider a recent theoretical account of mind wandering, proposed by Smallwood (2013), in which a distinction is made between the "ignition point" and the “continuation" of a mind-wandering episode. When considering this more nuanced account of mind wandering, it becomes clear that questions pertaining to the intentionality of a given episode can become ambiguous because it is not obvious whether, for example, a reported case of "unintentional mind wandering" refers to a lack of intention in terms of the initiation of the episode or a lack of intention in terms of the continuation of the episode (or both). Indeed, as recently suggested (Seli, Ralph, et al., in press), one could unintentionally initiate an episode of mind wandering, yet later come to gain awareness of her mind wandering and intentionally decide to pursue it. In such a case, depending on how the participant interprets the question 
pertaining to the intentionality of his mind wandering, she could reasonably report that her mind wandering was intentional or unintentional.

Although the aforementioned problem might be resolved by developing more specific probing techniques, there is another, more serious, problem with the use of the terms "intentional" and "unintentional" mind wandering: Namely, that such terms have seemingly been conceptualized in terms of reflecting "guided" and "unguided" attention, respectively. Although unguided thought can, of course, occur unintentionally (i.e., despite people's best intentions to refrain from engaging such thought), a lack of intention is not a requirement of unguided thought. For instance, sitting on one's porch and woolgathering exemplifies a state that is characterized by unguided thought, but at the same time, the thoughts experienced in such a scenario often proceed without any effort to terminate them (in this sense, they are not "unintentional"). Indeed, such thoughts may even be triggered by a wilful attempt to disengage from the here and now. In such cases, then, these thoughts might be best referred to as "aintentional," insofar as they do not involve active guidance, nor do they emerge in spite of one's efforts to actively prevent them. Critically, however, in these cases, most researchers would presumably classify the individual's thoughts as reflecting mind wandering, not on the basis of intention (or lack thereof), but rather, because the thoughts were unguided. It is therefore our belief that when researchers have used the term "unintentional mind wandering," what they really had in mind in terms of the defining feature of mind wandering was a lack of guidance, and not necessarily thoughts that occurred unintentionally, despite people's best efforts to refrain from engaging in them.

To resolve this apparent problem, we propose that it is important to make a distinction between intentional/unintentional mind wandering and guided/unguided thought (for a similar 
proposal, see Christoff, Irving, Fox, Spreng, \& Andrews-Hanna, 2016; Irving, 2016). That is, rather than conceptualize mind wandering in terms of unintentional thought, it would seem more prudent to conceptualize it as reflecting unguided thought. Notably, however, research examining the intentionality of mind-wandering episodes could nevertheless provide important theoretical insights into the wandering mind. For instance, individuals with attentiondeficit/hyperactivity disorder (ADHD) and obsessive-compulsive disorder (OCD) may be particularly prone to experiencing thoughts that occur despite their best intentions to refrain from having them, whereas members of the non-clinical population might instead be more prone to experiencing a-intentional (and/or intentional) thoughts. Gaining insight into these potential differences could not only inform our understanding of why certain people's minds wander, but it could also inform the development potential methods of remediation that can be used to reduce the occurrence of such mind wandering. For these reasons, we do not advise that researchers abandon these terminologies, but rather, we suggest that they distinguish between the intentionality and the level of guidance of thoughts.

\section{Stimulus dependence and mind wandering}

Yet another way to define mind wandering is in terms of stimulus-independent thought (e.g. Smallwood \& Schooler, 2015; Stawarczyk et al., 2011; Teasdale et al., 1993; 1995). ${ }^{2}$ In a strict sense, "stimulus-independence" could be taken to imply that the thought under investigation exists in an internal, impermeable cell, oblivious to any prior perceptual experience(s) of one's environment. However, it seems unambiguously the case that all

\footnotetext{
${ }^{2}$ Notably, some researchers (e.g., Stawarczyk et al., 2011) have operationalized mind wandering not only in terms of stimulus-independence, but also in terms of some other defining property or properties (e.g., stimulusindependent and task-unrelated thought).
} 
internally focused thoughts must be supported by internal representations (i.e., memories) of prior perceptual experiences, rather than arising out of 'thin air' (Metzinger, in press). Rather than conceive of stimulus independence in the strict sense, then, most researchers use stimulusindependence to refer to a property of thoughts that "arise from intrinsic changes that occur within an individual [i.e., stimulus-independent thoughts]," while excluding as cases of mind wandering thoughts that arise from "extrinsic changes that are cued directly from perceptual events occurring in the external environment [i.e., stimulus-dependent thoughts]" (Smallwood \& Schooler, 2015, p. 490). In this sense, the term "stimulus-independent" is typically understood in terms of reflecting a mismatch between the content of one's thoughts and the immediate environmental context in which one is situated.

However, even if we agree that it is most sensible to constrain the definition of "stimulus independent" to stimuli in the immediate environment, it remains unclear how distant the thought in question must be from these stimuli to qualify as mind wandering. Consider, for example, the case in which a loud noise draws one's attention, initially eliciting thoughts about the potential for danger in the immediate environment, but ultimately resulting in thoughts that are no longer directly tied to the external environment - for instance, thoughts about a soldier's fearful experiences at war. In this scenario, the point at which the train of thought becomes stimulus independent is unclear.

Another (perhaps more dire) complicating issue is that stimulus independence is also a property of certain forms of task-related cognition. Indeed, certain tasks require information to be buffered over time and thus require task-relevant information to be maintained in a stimulusindependent form. For example, while completing a working-memory task, information from previous trials must be buffered in order for the participant to respond correctly. Similarly, good 
performance on certain tasks requires people to generate information, such as when participants perform creativity or category-generation tasks. Although these cases do not pose a direct problem to proponents of a "stimulus-independent" definition of mind wandering (e.g., Smallwood \& Schooler, 2015), they do suggest that this definition might, on its own, be problematic. Indeed, given that most researchers do not conceptualize mind wandering as taskrelevant cognition, and given that stimulus-independent thought can also be task-relevant thought, such a definition seems to be at odds with people's general understanding of mind wandering. Thus, while most conceptions of mind wandering would include some degree of distinction between one's thoughts and one's surroundings, strictly defining "mind wandering" along these lines could be overly inclusive because it would encompass situations such as deliberate memory retrieval.

\section{Minimizing confusions arising from different definitions of mind wandering}

Our review of the literature demonstrates that attempts to distinguish mind wandering along simple cardinal dimensions, such as its task-relatedness, intentionality, or stimulus independence fail to capture the rich variety of this experience with which we are all so familiar. These difficulties lead to the concern that researchers may be creating artificial distinctions between types of experience that actually share similar features, and also that investigators might be lumping together fundamentally different types of experience into the same category. We believe that these problems may be hampering the emergence of a mature scientific account of mind wandering.

Given this concern, one might wonder how it is possible that people have managed to use the term "mind wandering" reasonably effectively in everyday life. We suggest that this has been made possible because in some (perhaps even many) cases, the meaning of the term "mind 
wandering" is dictated or informed by the context in which it is used. For instance, if a student says to her friend; "I mind-wandered a lot in class today," the context implies that there was a primary task (i.e., attending to the lecture) and that the student experienced task-unrelated thoughts. Similarly, if an individual were to say, "I was just sitting on the dock of the bay, mind wandering," most people would likely use the contextual information to infer that there was no primary task in which the individual was engaged, and that he had allowed his mind to wander (i.e., he engaged in intentional mind wandering).

Although we can often effectively use the term "mind wandering" in everyday life, in the scientific domain - in which precision in terminology is of the utmost importance - one possible problem arising from the generic use of "mind wandering" is that sometimes the context is unclear, and so the reader is forced to make assumptions about the specific conceptualization of mind wandering that authors have in mind (e.g., "Are they simply referring to task-unrelated thought or do they mean task-unrelated and unintentional thought?). Another problem that sometimes arises from the generic use of mind wandering is that, although researchers may be entertaining a specific definition, they may not effectively translate it into the operational definition of mind wandering they provide for their participants during task instruction. For example, despite conceptualizing mind wandering as internally focused thought, Seli, Cheyne, and Smilek (2013) operationalized mind wandering as, "thinking about task-unrelated things (e.g., plans with friends, an upcoming exam, etc.)" (p. 2), which did not explicitly make an 'internal focus' a requirement for mind-wandering reports. Importantly, this operational definition of mind wandering allowed and, strictly interpreted, required participants to report externally focused thought (e.g., distractions, loud noises, etc.) as 'mind wandering', in conflict with the authors' conception. Similarly, Blanchard et al. (2014), although conceptualizing mind 
wandering as "unintentional lapses of attention" (p. 55), did not ensure that participants' reports of "mind wandering" were indeed accompanied by a lack of intention. Thus, the authors' operational definition allowed reports of "mind wandering" to include thoughts that were engaged intentionally, even though such thoughts were, according to the researchers, not reflective of mind wandering. In these (and other related) cases, a discrepancy between the researchers' conceptual understanding of mind wandering and their explicit operational definition may produce inconsistencies, confusions, and a general lack of clarity in the literature.

With these considerations in mind, it may seem sensible for the field to simply abandon the generic use of the term "mind wandering" in favor of more nuanced and qualified terms, such as "unintentional mind wandering," "unintentional task-unrelated thought," or "intentional stimulus-independent thought"; this strategy would undoubtedly clarify what researchers mean. However, we maintain that "mind wandering" has utility as an umbrella term for a specific area of research (in the same way that, for example, "attention," "memory," and "creativity" do). It hardly seems sensible, for instance, to argue that the term "cognition" should be abandoned because definitions of visual cognition do not fully capture those of numerical cognition.

A second solution is to provide a specific definition of mind wandering - characterized by a set of necessary and sufficient conditions - thus treating the phenomenon as belonging to a “classical view" of category membership. Although appealing, any such definition will be necessarily arbitrary. More important, based on the foregoing considerations, any classical definition will necessarily leave out instances that could reasonably be characterized as mind wandering. Suppose, for example, that we were to propose a classical definition of mind wandering as unintentionally engaged, task-unrelated thought. Although some researchers might well agree with this conceptualization, such a classical definition would exclude cases in which 
one "daydreams" in the absence of a task, or cases in which one intentionally disengages from a task in the service of woolgathering. In response to such a classical definition, then, another group of researchers might proclaim our definition too restrictive, and that it ought to also include task-independent thoughts, or perhaps intentionally engaged thoughts. Because this process would be arbitrary, it would allow no logical resolution.

Instead, we argue that the most sensible way to move the field forward is to adopt a third approach by which we acknowledge that the mind-wandering state is a rich, complex, and multidimensional "cluster concept" (Metzinger, in press) containing a family of experiences that share some features but differ in others. Critically, this approach would allow us to specify the most prototypical case of mind wandering, which would in turn serve to guide future research, while also leaving open the door for the less prototypical members of the conceptual family to be considered while encouraging researchers to clearly articulate when their use of the term refers to less prototypical cases.

\section{Mind wandering as a family of experiences}

Consider ... the proceedings that we call "games". I mean board-games, card-games, ballgames, Olympic games, and so on. What is common to them all? —Don't say: "There must be something common, or they would not be called 'games' "—-but look and see whether there is anything common to all. - For if you look at them you will not see something that is common to all, but similarities, relationships, and a whole series of them at that. To repeat: don't think, but look! — Look for example at board-games, with their multifarious relationships. Now pass to card-games; here you find many correspondences with the first group, but many common features drop out, and others appear. When we pass next to ball-games, much that is common is retained, but much is 
lost. - Are they all 'amusing'? Compare chess with noughts and crosses. Or is there always winning and losing, or competition between players? Think of patience. In ball games there is winning and losing; but when a child throws his ball at the wall and catches it again, this feature has disappeared. Look at the parts played by skill and luck; and at the difference between skill in chess and skill in tennis. Think now of games like ring-a-ring-a-roses; here is the element of amusement, but how many other characteristic features have disappeared! And we can go through the many, many other groups of games in the same way; can see how similarities crop up and disappear. And the result of this examination is: we see a complicated network of similarities overlapping and crisscrossing: sometimes overall similarities, sometimes similarities of detail. I can think of no better expression to characterize these similarities than "family resemblances"; for the various resemblances between members of a family: build, features, colour of eyes, gait, temperament, etc. etc. overlap and criss-cross in the same way. - And I shall say: 'games' form a family. (Wittgenstein, 1953, pp. 31-32)

Although some categories have a common set of necessary and sufficient defining features that apply to all members of the category (e.g., odd numbers all have a remainder of 1 when divided by 2), most categories are held together by overlapping subsets of similarities, or "family resemblances," rather than a common thread that runs through all members (Wittgenstein, 1953). Eleanor Rosch and colleagues more recently distinguished between categories for which membership is "digital" (i.e., all-or none; Rosch \& Mavis, 1975, p. 573) and "natural categories" (Rosch, 1973; Rosch \& Mavis 1975, p. 574) for which membership is “analog” (Rosch \& Mavis 1975, p. 574); in analog categories, some members are better 
examples than others (see also McCloskey \& Glucksberg, 1978). Rosch and Mavis (1975, p. 575), "viewed natural semantic categories as networks of overlapping attributes." According to this view, natural categories or concepts include exemplars that vary in prototypicality, with highly prototypical members having attributes that overlap with the most other exemplars of the category (see also Zadeh, 1965, who similarly used the term, "fuzzy set" to describe "a 'class' with a continuum of grades of membership.” p. 339).

We suggest that mind wandering is best considered a natural category with graded membership (for a similar view, see Metzinger, in press). Indeed, there are some experiences that we would likely all agree qualify as mind wandering, other experiences that are more debatable, and still others that would appear to fall outside of this category. From this perspective, mindwandering experiences can be characterized along a series of dimensions or attributes that determine the overall membership or family-resemblances structure of the "mind wandering" category. However, in order to quantify the level of membership of given cognitive experience in the category of mind wandering, one requires a point of reference, or a prototypical case of mind wandering to which the cognitive experience in question can be compared (Rosch \& Mavis, 1975). Consistent with this view, in recently discussing "open concepts" (i.e., concepts, such as mind wandering, that are characterized by fuzzy boundaries), Lilienfield (2017) noted that:

"...there is the risk of an open concept's being so imprecisely defined and porous in its boundaries that it is not at all apparent where it begins or ends. Open concepts are most likely to bear scientific fruit when tethered to a reasonably clear-cut implicit or contextual—but not a rigid or "operational” (see Green, 1992, for a thoughtful discussion)—definition, one that specifies a concept's place within a nomological network of convergent and discriminant 
correlates (Cronbach \& Meehl, 1955). Absent such a floating anchor, the boundaries of an open concept can contract or expand radically at the whim of investigators, clinicians, or policymakers" (Lilienfield, 2017, p. 143).

Thus, while we have argued for the importance of acknowledging the complexity and diversity of the notion of mind wandering, we also argue that it is equally important to "tether" this concept to an implicit definition, or a "prototypical case." Indeed, if we fail to tether the concept of mind wandering to an implicit prototypical case, then we might lose our moorings to be cast adrift in a stagnant estuary of generic "thinking," wherein "intentionally engaged, taskdirected thought" and "unintentionally engaged, task-unrelated thought" share equal membership in the category of mind wandering. Although proposing a prototypical case of mind wandering is, to some extent, an arbitrary practice, consideration of the prototypical case of mind wandering can be guided by consensus in the extant literature on mind wandering and by the general consensus among researchers of mind wandering.

\section{Identifying a Prototypical Case of Mind Wandering}

To specify a prototypical instance of mind wandering, we use slightly modified versions of the dimensions identified above, and we highlight that even this prototypical instance has somewhat fuzzy boundaries. Indeed, none of the dimensions underlying the specification of a prototypical case reflect all-or-none dimensions, but each are instead somewhat graded. With this in mind, we suggest that a prototypical case of mind wandering includes thoughts that are simultaneously (a) not focused on an internal or external task (b) unguided, (c) and not closely tied to an immediate external stimulus. We consider each of these stipulations in turn, keeping in 
mind that, together, they are meant to describe only a prototypical case of mind wandering and not every case of mind wandering.

\section{Thoughts that are not focused on an internal or external task}

Some might argue that human thought is best characterized as mostly reflecting on-task focus that, from time to time, is interrupted by moments of mind wandering. We suggest, however, that the opposite position is more plausible: That is, that our thoughts are primarily characterized by mind wandering, which is occasionally interrupted by on-task focus; as such, mind wandering is the default state of the human cognitive system (e.g., Antrobus, Singer, \& Greenberg, 1966; Buckner, Andrews-Hanna, \& Schacter, 2008; Christoff et al., 2009; Kane et al., 2007; Kaufman \& Singer, 2011; Killingsworth \& Gilbert, 2010; Raichle et al., 2001; Singer, 1966; Smallwood \& Schooler, 2006). We argue that the prototypical case of mind wandering occurs when conscious thought is not focused on a particular task (be it an internally or externally oriented task). By this view, mind wandering may occur in task-independent contexts, when there is no identifiable task or activity to be thinking about at the moment: a characterization that seems consistent with people's general view that our thoughts tend to wander even when we are not explicitly attempting to perform a nominal task.

\section{Thoughts that are unguided}

To constrain our prototypical case of mind wandering further, in line with Irving (2016) and Christoff et al. (2016), we suggest that it reflects thoughts that are not guided or controlled from moment to moment (i.e., unguided thought). Indeed, as noted earlier, across numerous studies, unguided thought has frequently been implied in researchers' conceptualizations of mind wandering (e.g., Blanchard et al., 2014; Carciofo et al., 2014; Christoff et al., 2016; Qu et al., 2015; Irving, 2016; Rummel \& Boywitt, 2014; for more examples, see Seli, Risko, \& Smilek, 
2016a, Supplemental Materials), and such a conceptualization appears to be a sensible one.

Indeed, because guided thought is antithetical to most conceptualizations of mind wandering, we argue that when considering the prototypical case of mind wandering, it is reasonable that such a case be restricted to thoughts that lack guidance.

\section{Thoughts not closely tied to an immediate external stimulus or context}

Although some researchers have operationally defined mind wandering as reflecting stimulus-independent thought (e.g., Smallwood \& Schooler, 2015), this explicit conceptualization of mind wandering has not been particularly prominent in the literature. However, in line with Stawarczyk et al. (2011) and Smallwood and Schooler (2015), we argue that it is sensible to posit that (in addition to being task-independent and unguided) a prototypical case of mind wandering is stimulus-independent. Prototypical mind wandering, from this perspective, does not include thoughts that are directly associated with stimuli in one's immediate environment. We assume that few (if any) researchers would disagree with this proposition. Indeed, this conceptualization of mind wandering has thus far gone without criticism in the literature, and for good reason, it seems: Thoughts directly pertaining to stimuli in the environment would arguably be better classified as "external distractions" (in the case in which one is completing a separate focal task) or "perception" (in the case in which one is not) than “mind wandering” (Smallwood \& Schooler, 2015; Stawarczyk et al., 2011). Importantly, prototypical mind wandering need not be "stimulus independent" in the strictest sense, whereby the thought has never been related to any prior perceptual experience; nor must it require that the thought cannot be indirectly elicited by an immediate environmental cue (Metzinger, in press). Rather, it suggests that, at the precise moment at which one's mental experience is sampled, the thought reported is characterized by a focus on the internal (mental) world. 


\section{Other Properties of the Mind-Wandering Experience}

Notably, there are interesting and important dimensions of the mind-wandering experience that we have not included in our prototypical case. For instance, its valence, realism, topical stability, intentionality, level of meta-awareness, relation to a researcher-imposed task (in cases where there is such a task) ${ }^{3}$, temporal orientation, and depth, all of which seem to be important aspects of this cognitive experience. Although considering these dimensions of thought should allow researchers to obtain a richer appreciation of the causes and consequences of mind wandering, they have not been commonly used in its definition (neither implicitly nor explicitly). Thus, they should not contribute to its prototype (in the same way that one's definition of a car does not depend on whether it has winter tires or not - despite this being quite relevant to the driver).

That said, we argue that assessing these additional dimensions of mind wandering can be exceptionally valuable (e.g., Gorgolewski et al., 2014; Medea et al., 2016; Ruby, Smallwood, Sackur, \& Singer, 2013; Stawarczyk et al., 2011; Smallwood et al., 2016). For instance, research has suggested that one's level of awareness of mind wandering affects performance on certain tasks, with lower levels of awareness associated with poorer performance than higher levels (Smallwood, McSpadden, \& Schooler, 2007). Moreover, we know that information about the depth of mind-wandering episodes can provide a more nuanced understanding of the consequences of mind wandering, with behaviors such as fidgeting emerging only when one is

\footnotetext{
3 This dimension refers to whether the thoughts in question are (un)related to a researcher-imposed task, and would seem particularly important to address in cases where researchers are strictly interested in examining TUT, as traditionally defined (that is, in terms of thoughts that are unrelated to a researcher-imposed task, as opposed to any given primary task).
} 
deeply absorbed in mind wandering (Seli, Carriere, et al., 2014). Likewise, research has found that bouts of mind wandering that are characterized by participants as "negative" are associated with poorer task performance compared with bouts of mind wandering that are characterized as "neutral" or "positive" (Banks, Welhaf, Hood, Boals, \& Tartar, 2016). Given the demonstrable benefits of adopting a more nuanced approach to understanding these dimensions of mind wandering, we believe it will be important for researchers to continue to measure and test hypotheses about these different dimensions.

\section{A Taxonomy for Identifying a Prototypical Case of Mind Wandering}

To formalize the foregoing properties of a prototypical case of mind wandering, we direct the reader to Figure 2, in which we present a diagram depicting the hierarchical relations of these different properties. Given that recent studies have reported that participants sometimes report "no thought content" when presented with a thought probe (e.g., Ward \& Wegner, 2013), before consulting this hierarchy one must first ensure that the participant is indeed thinking about something in the first place. Although this may seem to be a negligible point because of its obviousness, the vast majority of research on the topic of mind wandering (including much of the work from our own labs) has not provided participants with an option to report no thought content, so it will clearly be important for researchers to begin providing response options that allow the participant to report on these instances of no thought (if only to devise tests of the validity of such reports). After verifying that a thought did indeed occur, we can begin in the uppermost row of the diagram (section A), "Human Thought," which is subdivided into thought that is guided (which also indicates whether participants were engaged in a primary task or not) and thought that is unguided (section B). At this section of the hierarchy, if researchers are interested in isolating the prototypical case of mind wandering, they must ensure that the thought 
in question is unguided (and hence, task-independent). In cases where a given thought is classified as unguided, the researcher must then determine whether the thought is closely tied to an immediate external stimulus: In the case that it is not, this thought would qualify as the prototypical case of mind wandering (denoted by the green box in section $\mathrm{C}$ of Figure 2). In section D (Figure 2), we present some of the many dimensions of mind wandering, which, as we note above, will be important for enhancing conceptual clarity in the field of mind wandering.

Please insert Figure 2 here

In order to identify the prototypical case, here we provide an example of a thought-probe sequence that researchers might consider employing in future work on the topic:

(1) Were you just thinking about anything? ${ }^{4}$ (Figure 2, Row A)

(2) Were you in control of/guiding your thoughts? (Figure 2, Row B)

(3) Were your thoughts internally focused (as opposed to being directly focused on something in the external environment)? (Figure 2, Row C)

\section{Benefits of the Family-Resemblances Approach}

The family-resemblances approach to the study of mind wandering will sharpen the operational definitions of the concept of mind wandering because it highlights the need for research to be able describe which attributes of the experience are the focus of investigation (Metzinger, in press). Importantly, this greater precision of measurement will not be at the cost

\footnotetext{
${ }^{4}$ Note that, in the case that participants are completing a researcher-imposed task, it would be useful for the researcher to specify that thoughts pertaining to the task qualify as "thinking about something."
} 
of losing touch with the rich phenomenon that we as experiencers are familiar with because it helps describe the richness of the subjective phenomenon (for a summary of the pros and cons of each of the potential solutions listed above, see Table 1).

Please insert Table 1 here

Importantly, the prototypical case of mind wandering identified above fits rather well with the prominent theoretical accounts of mind wandering, although it would seem that each account must be qualified to some extent. For instance, the prototypical case includes goal-directed (but unguided) thought, which can, according to Klinger and colleagues' (Klinger, 1987; Klinger \& Cox, 2004) Current Concerns hypothesis, characterize moments of mind wandering (e.g., when an individual experiences unguided, but goal-directed thought about how to improve his romantic relationship). We might simply qualify Klinger's hypothesis to note that, when a current concern becomes the focus of guided thought, the thought is no longer a prototypical instance of mind wandering, but might be characterized by some as reflecting a moment of focal thought following a task switch. The prototypical case of mind wandering also clearly allows for moments of control failures, as posited by Kane and colleagues. (e.g., Kane \& McVay 2012; McVay \& Kane, 2010), although it does not require failures of control, as the prototypical case encompasses situations in which a person chooses not to exert control (e.g., woolgathering while sitting on a dock). Finally, our prototypical case of mind wandering is consistent with the "resource account" of mind wandering (Smallwood \& Schooler, 2006), and particularly with the notion that mind wandering requires conscious resources, or accesses to the global workspace (Smallwood, 2010), as it is fundamentally a conscious experience. Yet, the prototypical case 
excludes situations in which one's thoughts are guided by executive resources in a controlled manner, which is somewhat contrary to the implied suggestions of some articulations of the 'resource account' of mind wandering. Interestingly, applying current theoretical accounts to the prototypical case of mind wandering proposed here already begins to show a key added benefit of clearly articulating a prototypical view of mind wandering: namely, that existing theories must include more nuance to explain the prototypical case.

Critically, although we propose a prototypical case of mind wandering, we nevertheless maintain that it will be exceptionally important for researchers to view mind wandering as a family of heterogeneous experiences with common and distinct features. As such, we argue that instances of thought that do not present themselves as prototypical cases of mind wandering (for example, stimulus-independent thought that occurs with intention) should still be categorized in terms of reflecting mind wandering so long as they share at least some features with the prototypical case. In taking this course of action, we avoid the problems that are inherent in arbitrarily providing a classical definition of mind wandering while providing a point of reference to which researchers can compare different types of thoughts in order to determine their family resemblance within the mind-wandering category. In addition, this course of action allows us to retain the term "mind wandering," which is useful because it denotes the "mindwandering" family and implies that distinct concepts within this family are similar to each other, perhaps in important ways. Of course, whether researchers are interested in examining the prototypical case of mind wandering (as presented here), non-prototypical cases, or both, they must ensure that their methods of assessing mind wandering are sensitive to the different properties of interest. 


\section{Implications of a family-resemblances approach to the study of mind wandering}

Mind wandering is a fuzzy concept, and a widely agreed upon definition of mind wandering - with necessary and sufficient conditions - is not forthcoming. This limitation has a number of implications for future scientific investigations. First, because family resemblances are determined by both common and distinct features, it will be increasingly important to assess multiple features of experience at the same time. This approach, which is common to daily-life investigations of mind wandering (e.g., Kane et al., 2007; Klinger, 1978-79; Klinger \& Cox, 1987-88; Song \& Wang, 2012), but not used frequently in laboratory studies (but see Medea et al., 2016; Smallwood et al., 2016), asks participants to answer multiple experience-sampling probe questions about the contents of their experience, which thereby allows the researcher to identify common and distinct elements of experience. Understanding the differences between different aspects of experiences can be achieved through the use of multivariate statistical techniques that reduce one's data into various dimensions that can be compared to other measures (such as neural function) to determine whether they share common features or mechanisms. This approach appears to indicate that there are stable features of experience in different samples of participants and, consistent with a family-resemblance account of the mindwandering state, that these features vary in their relation to neurocognitive measures (e.g., Smallwood et al., 2016).

Taking a family-resemblances approach also highlights the need for the field to determine which precise dimensions of experience should be studied in the first place. One way to approach this problem is to ask participants to provide open-ended reports about the contents of their experiences. These open-ended responses could be categorized (by participants or independent 
raters) based on established or novel dimensions of interest. Although such open-ended reports can present interpretive challenges (such as requiring verbalization of potentially nonverbalizable experiences, reporting of deeply personal thoughts, or "punishing" mind-wandering reports by making them more effortful than on-task reports), they have been successfully employed in some studies examining the temporal focus of mind wandering (e.g., Smallwood, Nind, \& O’Connor, 2009). If sufficiently large corpuses of open-ended reports of mindwandering experiences can be collected, then these could be explored using text-mining techniques that may reveal novel and unknown dimensions to experience in the mind-wandering state. In addition, taking a family-resemblances approach of mind wandering might lead to increasing intellectual - if not methodological - connections among related phenomena that some might consider non-prototypical members of the mind-wandering category, such as spontaneous memories (autobiographical or semantic), earworms, depressive rumination, and so forth (e.g., Maillet \& Schacter, 2016). The fuzzy-set view of mind wandering readily brings forth the realization that neighboring constructs are directly relevant to each other, and so they should not be studied in isolation, residing in separate literatures.

Finally, and perhaps of most importance, a family-resemblances approach should prompt investigators to clearly identify, from the outset of their study design, what aspect(s) or dimension(s) of mind wandering they are interested in examining. Based on these dimensions of interest, they must then carefully craft thought probes to directly address these dimensions. Indeed, researchers will not only need to specify their operationalization of mind wandering in designing their study, but they will also have to carefully consider - and report fully - the verbatim descriptions, definitions, and/or examples of mind wandering that they provide to research participants. In this way, readers can judge whether the authors' and the participants' 
understandings were aligned, and thus whether the data really bear on the ostensible questions of interest. Lastly, the conclusions drawn from studies ought to remain constrained to the dimensions assessed. Researchers should be cautious in drawing overarching conclusions about mind wandering, such as "all mind wandering is associated with poor performance" or "mind wandering more makes you more creative" (for step-by-step guidelines for future research, see Table 2).

-Please insert Table 2 here

\section{Summary and Concluding Remarks}

Let us now return to Quine's (1936) quote, with which we opened this article: “The less a science has advanced, the more its terminology tends to rest on an uncritical assumption of mutual understanding” (p. 90). Having considered the various conceptual confusions that have arisen from the common belief in a "mutual understanding" of the concept of mind wandering, it is apparent that Quine's statement applies to modern research in our field. Indeed, most mindwandering researchers (ourselves included) have, from time to time, made the "uncritical [or implicit] assumption" that everyone's conceptualization of mind wandering is mutually understood and agreed upon, despite clear differences in operationalizations across laboratories.

Despite the important differences in the operational definitions employed, researchers have tended to discuss "mind wandering" in broad-brush terms, failing to carefully consider how the specific construct that they are investigating is related to, or different from, constructs discussed in other studies. As a direct consequence of this practice, some researchers who have explicitly endorsed a very specific view of mind wandering (e.g., as reflecting "task-unrelated" thought) have nevertheless theoretically integrated their findings with those obtained from studies assess different varieties of mind wandering (e.g., mind wandering in task-free settings), 
even though their formal definition does not allow these latter thoughts to qualify. Given this seemingly contradictory use of terminology, it is also apparent that Klinger and Cox (1987-88) were correct in noting that "It would do violence to the language, and is undoubtedly unattainable in practice..." (pp. 17-18) to define mind wandering (or daydreaming) according to a single dimension. In light of these problems, we propose that mind wandering instead should be viewed by researchers as a family of experiences, and that, moving forward, they should (a) clearly identify which dimensions of mind wandering they are interested in investigating, (b) carefully develop/select thought probes and other assessments of mind wandering so that they can directly address these dimensions of interest, (c) constrain their conclusions to the specific dimensions of mind wandering assessed and limit their theoretical interpretations only to the dimensions that were targeted for study.

As the field of mind-wandering research matures within this more multi-faceted perspective, it seems likely that certain qualities (e.g. a lack of guidance, stimulus independence) will emerge as especially applicable in many cases, whereas others (e.g. meta-awareness, topical stability) will prove more narrowly pertinent. However, even such broad generalizations are likely to find exceptions (as for example when an external event distracts the mind from deliberate internal calculations). By acknowledging the various states that can be reasonably characterized as mind wandering while simultaneously specifying the dimensions that are relevant to any particular investigation, we can begin to unravel the many strands that contribute to this ubiquitous yet elusive category of mental experience. 


\section{References}

Antrobus, J. S., Singer, J. L., and Greenberg, S. (1966). Studies in the stream of consciousness: experimental enhancement and suppression of spontaneous cognitive processes. Perceptual \& Motor Skills, 23, 399-417.

Baird, B., Smallwood, J., Mrazek, M. D., Kam, J. W., Franklin, M. S., \& Schooler, J. W. (2012). Inspired by distraction mind wandering facilitates creative incubation. Psychological Science, 23, 1117-1122.

Baird, B., Smallwood, J., \& Schooler, J. W. (2010, April). I can shake that feeling: Positive mind-wandering prevents the deterioration of mood. Poster presented at Towards a Science of Consciousness conference, Tucson, AZ.

Banks, J. B., Welhaf, M. S., Hood, A. V., Boals, A., \& Tartar, J. L. (2016). Examining the role of emotional valence of mind wandering: All mind wandering is not equal. Consciousness and Cognition, 43, 167-176.

Blanchard, N., Bixler, R., Joyce, T., \& D’Mello, S. (2014). Automated physiological-based detection of mind-wandering during learning. In S. Trausan-Matu, K. Boyer, M. Crosby, \& K. Panourgia (Eds.), Lecture Notes in Computer Science: Vol. 8474. Intelligent tutoring systems (pp. 55-60). New York, NY: Springer Science+Business Media. doi:10.1007/978-3-319-07221-0_7

Buckner, R. L., Andrews-Hanna, J. R., \& Schacter, D. L. (2008). The brain's default network. Annals of the New York Academy of Sciences, 1124, 1-38.

Callard, F., Smallwood, J., Golchert, J., \& Margulies, D. S. (2013). The era of the wandering mind? Twenty-first century research on self-generated mental activity. Frontiers in Psychology, 4, 891. 
Carciofo, R., Du, F., Song, N., \& Zhang, K. (2014). Mind-wandering, sleep quality, affect, and chronotype: An exploratory study. PLoS ONE, 9(3), Article e91285. doi:10.1371/journal.pone.0091285

Casner, S. M., \& Schooler, J. W. (2013). Thoughts in Flight Automation Use and Pilots' TaskRelated and Task-Unrelated Thought. Human Factors: The Journal of the Human Factors and Ergonomics Society, 0018720813501550.

Christoff, K., Gordon, A. M., Smallwood, J., Smith, R., \& Schooler, J. W. (2009). Experience sampling during fMRI reveals default network and executive system contributions to mind wandering. Proceedings of the National Academy of Sciences, 106, 8719-8724.

Christoff, K., Irving, Z. C., Fox, K. C., Spreng, R. N., \& Andrews-Hanna, J. R. (2016). Mindwandering as spontaneous thought: a dynamic framework. Nature Reviews Neuroscience. doi:10.1038/nrn.2016.113

Csikszentmihalyi, M., \& Larson, R. (1987). Validity and reliability of the experience sampling method: Mental disorders in their natural settings. Journal of Nervous and Mental Disease, 175, 526-536.

de Vries, M. C., Dijkman-Caes, C., \& Delespaul, P. (1990). The sampling of experience: A method of measuring the co-occurrence of anxiety and depression in daily life. In J. D. Maser \& C. R. Cloninger (Eds.), Comorbidity of mood and anxiety disorders (pp. 707726). Washington, DC: American Psychiatric Press.

Feng, S., D’Mello, S., \& Graesser, A. C. (2013). Mind wandering while reading easy and difficult texts. Psychonomic Bulletin \& Review, 20, 586-592.

Forster, S., \& Lavie, N. (2009). Harnessing the wandering mind: The role of perceptual load. Cognition, 111, 345-355. 
Franklin, M. S., Broadway, J. M., Mrazek, M. D., Smallwood, J., \& Schooler, J. W. (2013). Window to the wandering mind: Pupillometry of spontaneous thought while reading. The Quarterly Journal of Experimental Psychology, 66, 2289-2294.

Gargiulo, S. (2013, October 30). Daydream believer: Is a wandering mind a creative mind? CNN Thinking Business. http://www.cnn.com/2013/10/30/business/daydream-believer$\underline{\text { is-a-wandering/ }}$

Giambra, L. M. (1989). Task-unrelated thought frequency as a function of age: a laboratory study. Psychology and Aging, 4, 136-143.

Golchert, J., Smallwood, J., Jefferies, E., Seli, P., Huntenburg, J. M., Liem, F., ... \& Margulies, D. S. (2017). Individual variation in intentionality in the mind-wandering state is reflected in the integration of the default-mode, fronto-parietal, and limbic networks. NeuroImage, 146, 226-235.

Gorgolewski, K. J., Lurie, D., Urchs, S., Kipping, J. A., Craddock, R. C., Milham, M. P., ... \& Smallwood, J. (2014). A correspondence between individual differences in the brain's intrinsic functional architecture and the content and form of self-generated thoughts. PloS one, 9(5), e97176.

Guilford, J. P. (1967). The nature of human intelligence. New York, NY: McGraw-Hill.

Hao, N., Wu, M., Runco, M. A., \& Pina, J. (2015). More mind wandering, fewer original ideas: Be not distracted during creative idea generation. Acta Psychologica, 161, 110-116. Hulburt, R. T. (1997). Randomly sampling thinking in the natural environment. Journal of Consulting and Clinical Psychology, 65, 941-944.

Irving, Z. C. (2016). Mind-wandering is unguided attention: accounting for the "purposeful" wanderer. Philosophical Studies, 173, 547-571. 
Jing, H.G., Szpunar, K.K., \& Schacter, D.L. (2016). Interpolated testing influences focused attention and improves integration of information during a video-recorded lecture. Journal of Experimental Psychology: Applied, 22, 305-318.

Kane, M. J., Brown, L. H., McVay, J. C., Silvia, P. J., Myin-Germeys, I., \& Kwapil, T. R. (2007). For whom the mind wanders, and when an experience-sampling study of working memory and executive control in daily life. Psychological Science, 18, 614-621.

Kane, M. J., \& McVay, J. C. (2012). What mind wandering reveals about executive-control abilities and failures. Current Directions in Psychological Science, 21, 348-354.

Kaufman, S. B., and Singer, J. L. (2011, December 22). The Origins of Positive-Constructive Daydreaming [Web log comment]. Retrieved from https://blogs.scientificamerican.com/guest-blog/the-origins-of-positive-constructivedaydreaming/ [accessed February 13, 2017].

Killingsworth, M. A., \& Gilbert, D. T. (2010). A wandering mind is an unhappy mind. Science, $330,932$.

Klinger, E. (1978-79). Dimensions of thought and imagery in normal waking states. Journal of Altered States of Consciousness, 4, 97-113

Klinger, E. (1987). Current concerns and disengagement from incentives. In Motivation, intention, and volition (pp. 337-347). Springer Berlin Heidelberg.

Klinger, E., \& Cox, W. M. (1987-88). Dimensions of thought flow in everyday life. Imagination, Cognition and Personality, 7, 105-128.

Klinger, E., \& Cox, W. M. (2004). Motivation and the theory of current concerns. Handbook of motivational counseling: Concepts, approaches, and assessment, 3-27. 
Levinson, D. B., Smallwood, J., \& Davidson, R. J. (2012). The persistence of thought evidence for a role of working memory in the maintenance of task-unrelated thinking. Psychological Science, 23, 375-380.

Lilienfeld, S. O. (2017). Microaggressions: Strong claims, inadequate evidence. Perspectives on Psychological Science, 12, 138-169.

Mason, M. F., Norton, M. I., Van Horn, J. D., Wegner, D. M., Grafton, S. T., \& Macrae, C. N. (2007). Wandering minds: the default network and stimulus-independent thought. Science, 315, 393-395.

Medea, B., Karapanagiotidis, T., Konishi, M., Ottaviani, C., Margulies, D., Bernasconi, A., ... \& Smallwood, J. (2016). How do we decide what to do? Resting-state connectivity patterns and components of self-generated thought linked to the development of more concrete personal goals. Experimental Brain Research. doi: 10.1007/s00221-016-4729-y

Metzinger, T. (in press). Why is mind wandering interesting for philosophers? In K. C. R Fox \& K. Christoff (Eds.), The Oxford Handbook of Spontaneous Thought: Mind-wandering, Creativity, Dreaming, and Clinical Conditions. New York: Oxford University Press.

Mooneyham, B. W., \& Schooler, J. W. (2013). The costs and benefits of mind-wandering: a review. Canadian Journal of Experimental Psychology/Revue Canadienne de Psychologie Expérimentale, 67, 11-18.

Mooneyham, B. W., \& Schooler, J. W. (2016). Mind wandering minimizes mind numbing: Reducing semantic-satiation effects through absorptive lapses of attention. Psychonomic Bulletin \& Review. doi: 10.3758/s13423-015-0993-2

Maillet, D., \& Schacter, D. L. (2016). From mind wandering to involuntary retrieval: Age-related differences in spontaneous cognitive processes. Neuropsychologia, 80, 142-156. 
McCloskey, M.E., \& Glucksbert, S. (1978). Natural categories: Well defined or fuzzy sets? Memory and Cognition, 6, 462-472.

McKiernan, K. A., D'Angelo, B. R., Kaufman, J. N., \& Binder, J. R. (2006). Interrupting the "stream of consciousness": an fMRI investigation. Neuroimage, 29, 1185-1191.

McVay, J. C., \& Kane, M. J. (2009). Conducting the train of thought: working memory capacity, goal neglect, and mind wandering in an executive-control task. Journal of Experimental Psychology: Learning, Memory, and Cognition, 35, 196-204.

Medea, B., Karapanagiotidis, T., Konishi, M., Ottaviani, C., Margulies, D., Bernasconi, A., ... \& Smallwood, J. (2016). How do we decide what to do? Resting-state connectivity patterns and components of self-generated thought linked to the development of more concrete personal goals. Experimental Brain Research. doi: doi:10.1007/s00221-016-4729-y

Mrazek, M. D., Smallwood, J., Franklin, M. S., Chin, J. M., Baird, B., \& Schooler, J. W. (2012). The role of mind-wandering in measurements of general aptitude. Journal of Experimental Psychology: General, 141, 788-798.

Phillips, N. E., Mills, C., D'Mello, S., \& Risko, E. F. (2016). On the influence of re-reading on mind wandering. The Quarterly Journal of Experimental Psychology, 69, 2338-2357.

Qu, W., Ge, Y., Xiong, Y., Carciofo, R., Zhao, W., \& Zhang, K. (2015). The relationship between mind-wandering and dangerous driving behavior among Chinese drivers. Safety Science, $78,41-48$.

Quine, W. (1936). Truth by convention. In O. Lee (Ed.), Philosophical essays for Alfred North Whitehead (pp. 90-124). New York: Longmans, Green and Co.

Raichle, M. E. (2015). The brain's default mode network. Annual Review of Neuroscience, 38, 433-447. 
Raichle, M. E., MacLeod, A. M., Snyder, A. Z., Powers, W. J., Gusnard, D. A., \& Shulman, G. L. (2001). A default mode of brain function. Proceedings of the National Academy of Sciences, 98, 676-682.

Rosch, E.H. (1973). Natural categories. Cognitive Psychology, 4, 328-350.

Rosch, E.H., \& Mervis, C.B. (1975). Family resemblances: Studies in the internal structure of categories. Cognitive Psychology, 7, 573-605.

Ruby, F. J., Smallwood, J., Sackur, J., \& Singer, T. (2013). Is self-generated thought a means of social problem solving?. Frontiers in Psychology, 4, 962.

Rummel, J., \& Boywitt, C. D. (2014). Controlling the stream of thought: Working memory capacity predicts adjustment of mind-wandering to situational demands. Psychonomic Bulletin \& Review, 21, 1309-1315.

Rummel, J., Smeekens, B.A., \& Kane, M.J. (in press). Dealing with prospective memory demands while performing an ongoing task: Shared processing, increased on-task focus, or both? Journal of Experimental Psychology: Learning, Memory, and Cognition. http://dx.doi.org/10.1037/xlm0000359

Sapolsky, R. M. (2015, June 19). The benefits of mind-wandering. The Wall Street Journal. http://www.wsj.com/articles/the-benefits-of-mind-wandering-1434716243

Schooler, J. W. (2002). Re-representing consciousness: Dissociations between experience and meta-consciousness. Trends in Cognitive Sciences, 6, 339-344.

Schooler, J. W., Reichle, E. D., \& Halpern, D. V. (2004). Zoning out while reading: Evidence for dissociations between experience and metaconsciousness. In D. T. Levin (Ed.), Thinking and seeing: Visual metacognition in adults and children (pp. 203-226). Cambridge, MA: MIT Press. 
Seli, P. (2016). The Attention-Lapse and Motor Decoupling accounts of SART performance are not mutually exclusive. Consciousness and Cognition, 41, 189-198.

Seli, P., Carriere, J. S., Thomson, D. R., Cheyne, J. A., Martens, K. A. E., \& Smilek, D. (2014). Restless mind, restless body. Journal of Experimental Psychology: Learning, Memory, and Cognition, 40, 660-668.

Seli, P., Cheyne, J. A., \& Smilek, D. (2013). Wandering minds and wavering rhythms: Linking mind wandering and behavioral variability. Journal of Experimental Psychology: Human Perception and Performance, 39, 1-5.

Seli, P., Cheyne, J. A., Xu, M., Purdon, C., \& Smilek, D. (2015). Motivation, intentionality, and mind wandering: Implications for assessments of task-unrelated thought. Journal of Experimental Psychology: Learning, Memory, and Cognition, 41, 1417-1425.

Seli, P., Jonker, T. R., Cheyne, J. A., Cortes, K., \& Smilek, D. (2015). Can research participants comment authoritatively on the validity of their self-reports of mind wandering and task engagement?. Journal of Experimental Psychology: Human Perception and Performance, 41, 703-709.

Seli, P., Ralph, B. C., Risko, E. F., Schooler, J. W., Schacter, D. L., \& Smilek, D. (in press). Intentionality and meta-awareness of mind wandering: Are they one and the same, or distinct dimensions? Psychonomic Bulletin \& Review. doi:10.3758/s13423-017-1249-0

Seli, P., Risko, E. F. R., Purdon, C., \& Smilek, D. (2016). Intrusive thoughts: Linking spontaneous mind wandering and OCD symptomatology. Psychological Research. doi: DOI: 10.1007/s00426-016-0756-3 
Seli, P., Risko, E. F., \& Smilek, D. (2016a). Assessing the associations among trait and state levels of deliberate and spontaneous mind wandering. Consciousness and Cognition, 41, $50-56$.

Seli, P., Risko, E. F., \& Smilek, D. (2016b). On the necessity of distinguishing between unintentional and intentional mind wandering. Psychological Science, 27, 685-691.

Seli, P., Risko, E. F., Smilek, D., \& Schacter, D. L. (2016). Mind-wandering with and without intention. Trends in Cognitive Sciences, 20, 605-617.

Seli, P., Smallwood, J., Cheyne, J. A., \& Smilek, D. (2015). On the relation of mind-wandering and ADHD symptomatology. Psychonomic Bulletin \& Review, 22, 629-636. doi:10.3758/s13423-014-0793-0

Seli, P., Wammes, J. D., Risko, E. F., \& Smilek, D. (2015). On the relation between motivation and retention in educational contexts: The role of intentional and unintentional mindwandering. Psychonomic Bulletin \& Review. Advance online publication. doi:10.3758/s13423-015-0979-0

Singer, J. L. (1966). Daydreaming: An Introduction to the Experimental Study of Inner Experience. New York: Random House.

Singer, J. L., \& Antrobus, J. S. (1963). A factor-analytic study of daydreaming and conceptuallyrelated cognitive and personality variables. Perceptual and Motor Skills, 17, 187-209.

Singer, J. L., \& Antrobus, J. S. (1972). Daydreaming, imaginal processes, and personality: A normative study. In P. W. Sheehan (Ed.) The Function and Nature of Imagery (pp. 175202). New York: Academic Press, Inc.

Smallwood, J. (2010). Why the global availability of mind wandering necessitates resource competition: reply to McVay and Kane (2010). Psychological Bulletin. 
Smallwood, J. (2013). Distinguishing how from why the mind wanders: a process-occurrence framework for self-generated mental activity. Psychological bulletin, 139, 519-535.

Smallwood, J., Beach, E., Schooler, J. W., \& Handy, T. C. (2008). Going AWOL in the brain: Mind wandering reduces cortical analysis of external events. Journal of Cognitive Neuroscience, 20, 458-469.

Smallwood, J., Karapanagiotidis, T., Ruby, F., Medea, B., de Caso, I., Konishi, M., ... \& Jefferies, E. (2016). Representing Representation: Integration between the Temporal Lobe and the Posterior Cingulate Influences the Content and Form of Spontaneous Thought. PloS One, 11(4), e0152272.

Smallwood, J., McSpadden, M., \& Schooler, J. W. (2007). The lights are on but no one's home: Meta-awareness and the decoupling of attention when the mind wanders. Psychonomic Bulletin \& Review, 14, 527-533.

Smallwood, J., Nind, L., \& O'Connor, R. C. (2009). When is your head at? An exploration of the factors associated with the temporal focus of the wandering mind. Consciousness and Cognition, 18, 118-125.

Smallwood, J., \& Schooler, J. W. (2006). The restless mind. Psychological Bulletin, 132, 946958.

Smallwood, J., \& Schooler, J. W. (2015). The science of mind wandering: empirically navigating the stream of consciousness. Annual Review of Psychology, 66, 487-518.

Smeekens, B.A. \& Kane, M. J. (2016). Working memory capacity, mind wandering, and creative cognition: An individual-differences investigation into the benefits of controlled versus spontaneous thought. Psychology of Aesthetics, Creativity, and the Arts, 10, 389-415.

Smilek, D., Carriere, J. S., \& Cheyne, J. A. (2010). Out of mind, out of sight eye blinking as 
indicator and embodiment of mind wandering. Psychological Science, 21, 786-789.

Song, X., \& Wang, X. (2012). Mind wandering in Chinese daily lives-an experience sampling study. PloS One, 7(9), e44423.

Stawarczyk, D., Majerus, S., Maj, M., Van der Linden, M., \& D'Argembeau, A. (2011). Mindwandering: phenomenology and function as assessed with a novel experience sampling method. Acta Psychologica, 136, 370-381.

Szpunar, K. K., Khan, N. Y., \& Schacter, D. L. (2013). Interpolated memory tests reduce mind wandering and improve learning of online lectures. Proceedings of the National Academy of Sciences, 110, 6313-6317.

Teasdale, J. D., Dritschel, B. H., Taylor, M. J., Proctor, L., Lloyd, C. A., Nimmo-Smith, I., \& Baddleley, A. D. (1995). Stimulus-independent-thought depends on central executive resources. Memory \& Cognition, 23, 551-559

Teasdale, J. D., Proctor, L., Lloyd, C. A., \& Baddeley, A. D. (1993). Working memory and stimulus-independent thought: Effects of memory load and presentation rate. European Journal of Cognitive Psychology, 5, 417-433.

Tierney, J. (2010, June 29). Discovering the virtues of a wandering mind.

The New York Times (Findings column). http://www.nytimes.com/2010/06/29/science/29tier.html?ref science\&pagewanted all\&_r $\underline{0}$.

Unsworth, N., \& McMillan, B. D. (2013). Mind wandering and reading comprehension: Examining the roles of working memory capacity, interest, motivation, and topic experience. Journal of Experimental Psychology: Learning, Memory, and Cognition, 39, 832-842. 
Uzzaman, S., \& Joordens, S. (2011). The eyes know what you are thinking: eye movements as an objective measure of mind wandering. Consciousness and Cognition, 20, 1882-1886.

Wammes, J. D., Boucher, P. O., Seli, P., Cheyne, J. A., \& Smilek, D. (2016). Mind wandering during lectures I: Changes in rates across an entire semester. Scholarship of Teaching and Learning in Psychology, 2, 13-32.

Wammes, J. D., Seli, P., Cheyne, J. A., Boucher, P. O., \& Smilek, D. (2016). Mind wandering during lectures II: Relation to academic performance. Scholarship of Teaching and Learning in Psychology, 2, 33-48.

Ward, A. F., \& Wegner, D. M. (2013). Mind-blanking: when the mind goes away. Frontiers in psychology, 4, 650 .

Wittgenstein, L. (1953). Philosophical investigations (G. E. M. Anscombe, Trans.). New York, NY: Macmillan.

Yanko, M. R., \& Spalek, T. M. (2013a). Route familiarity breeds inattention: A driving simulator study. Accident Analysis \& Prevention, 57, 80-86.

Yanko, M. R., \& Spalek, T. M. (2013b). Driving with the wandering mind: The effect that mindwandering has on driving performance. Human Factors, 56, 260-269.

Zadeh, L.A. (1965). Fuzzy sets. Information and Control, 8, 338-353. 
Table 1. Summary of the pros and cons of each of the three potential methods to minimize concerns surrounding confusions arising from the use of different definitions of mind wandering.

\begin{tabular}{|c|c|c|}
\hline & Pros & Cons \\
\hline $\begin{array}{l}\text { Abandon the term } \\
\text { mind wandering }\end{array}$ & $\begin{array}{l}\text { Results in the use of more precise terms in } \\
\text { investigations of human thought, and } \\
\text { eliminates confusion surrounding what, } \\
\text { exactly, "mind wandering" means. }\end{array}$ & $\begin{array}{l}\text { "Mind wandering" has utility as an } \\
\text { umbrella term for a specific area of } \\
\text { research (in the same way that the } \\
\text { terms "attention" and "memory" } \\
\text { do). }\end{array}$ \\
\hline $\begin{array}{l}\text { Provide a precise } \\
\text { (classical) } \\
\text { definition of mind } \\
\text { wandering }\end{array}$ & $\begin{array}{l}\text { All researchers would use the same } \\
\text { terminology, and findings could be readily } \\
\text { generalizable across studies. }\end{array}$ & $\begin{array}{l}\text { The adopted classical definition } \\
\text { would be arbitrary, and it would } \\
\text { likely exclude many commonly } \\
\text { recognized forms of mind } \\
\text { wandering. }\end{array}$ \\
\hline $\begin{array}{l}\text { Adopt a family- } \\
\text { resemblances } \\
\text { approach }\end{array}$ & $\begin{array}{l}\text { Eliminates disagreement in terms of how } \\
\text { "mind wandering" should be defined. } \\
\text { Does not exclude commonly recognized } \\
\text { forms of mind wandering (e.g., deliberate } \\
\text { daydreaming). } \\
\text { Adds precision to operational definitions of } \\
\text { mind wandering because it highlights the } \\
\text { need for researchers to describe which } \\
\text { attributes of the experience they are } \\
\text { interested in. } \\
\text { May lead to increasing } \\
\text { intellectual/methodological connections } \\
\text { among related phenomena (e.g., earworms, } \\
\text { depressive rumination). } \\
\text { Provides a prototypical case of mind } \\
\text { wandering that can be used to tether this } \\
\text { construct to researchers' implicit and explicit } \\
\text { conceptualizations of mind wandering }\end{array}$ & $\begin{array}{l}\text { Findings would not be readily } \\
\text { generalizable across all studies } \\
\text { (although this approach would come } \\
\text { with the benefit of enhanced } \\
\text { specificity in terms of the variety - } \\
\text { or varieties - of mind wandering } \\
\text { under investigation). }\end{array}$ \\
\hline
\end{tabular}


Table 2. Step-by-step guidelines for future research

1. Researchers should clearly identify, from the outset of their study design, which dimension(s) of mind wandering they are interested in examining.

2. Researchers should not only specify their operationalization of mind wandering in designing their study and interpreting their data, but they should also carefully consider - and report fully - the verbatim descriptions, definitions, and/or examples that they provided to the participants (In this way, readers can judge whether the authors' and the participants' understandings were aligned, and thus, whether the data really bear on the ostensible questions of interest).

3. Perhaps most critically, the conclusions drawn from studies ought to remain constrained to the dimensions assessed, and researchers should be cautious in drawing overarching conclusions about mind wandering (e.g., "mind wandering is associated with enhanced creativity"), and they should limit their theoretical interpretations to the dimensions that were targeted for study. 


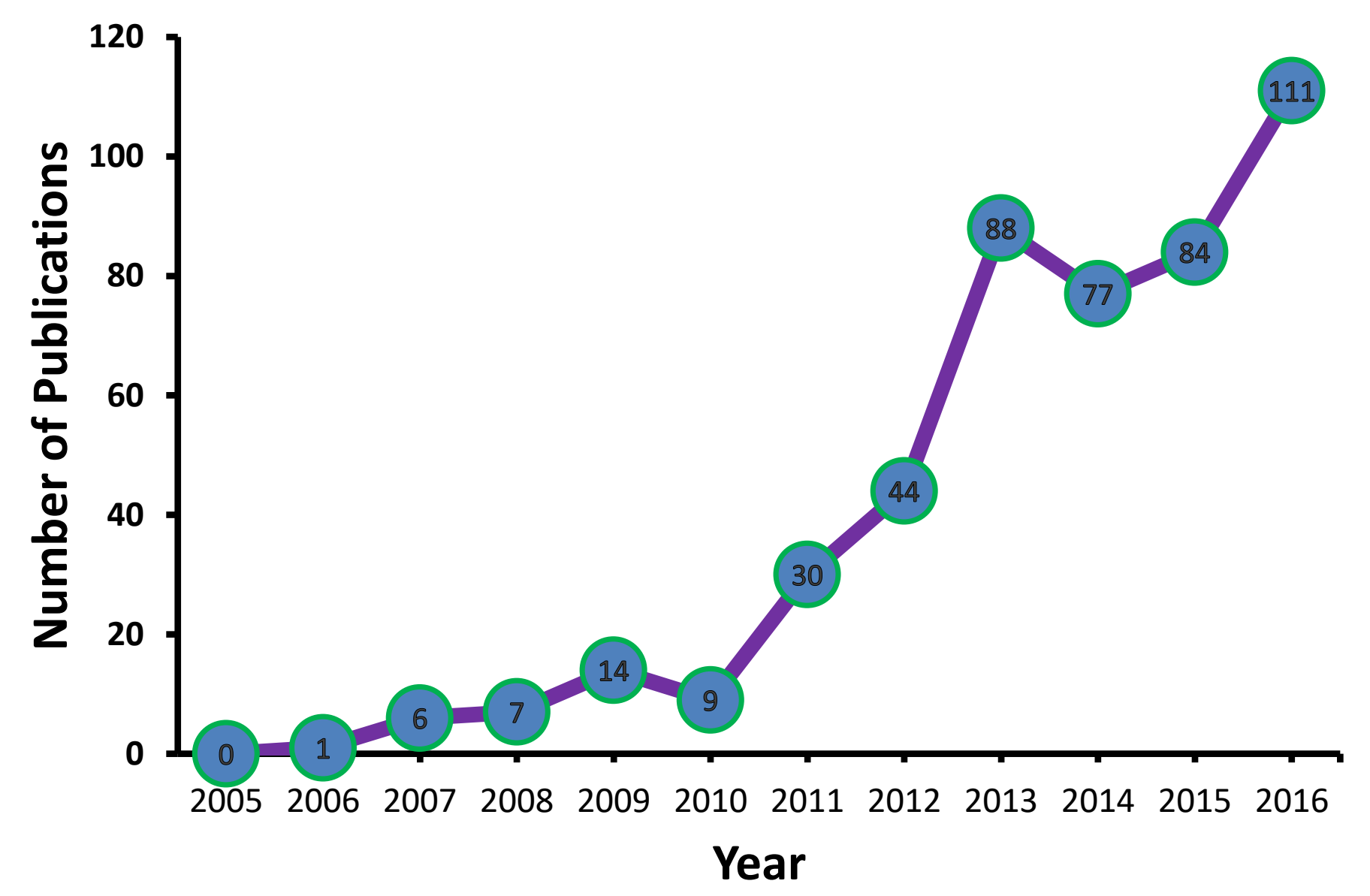

Figure 1. Number of publications focused on mind wandering from 2005 to 2016. The data for this figure were obtained (on March $16^{\text {th }}, 2017$ ) by conducting a pubmed.org search for any articles that used the terms "mind wandering" and "mind-wandering" in the title/abstract of the article (for a similar depiction, see Callard, Smallwood, Golchert, \& Marguiles, 2013). 


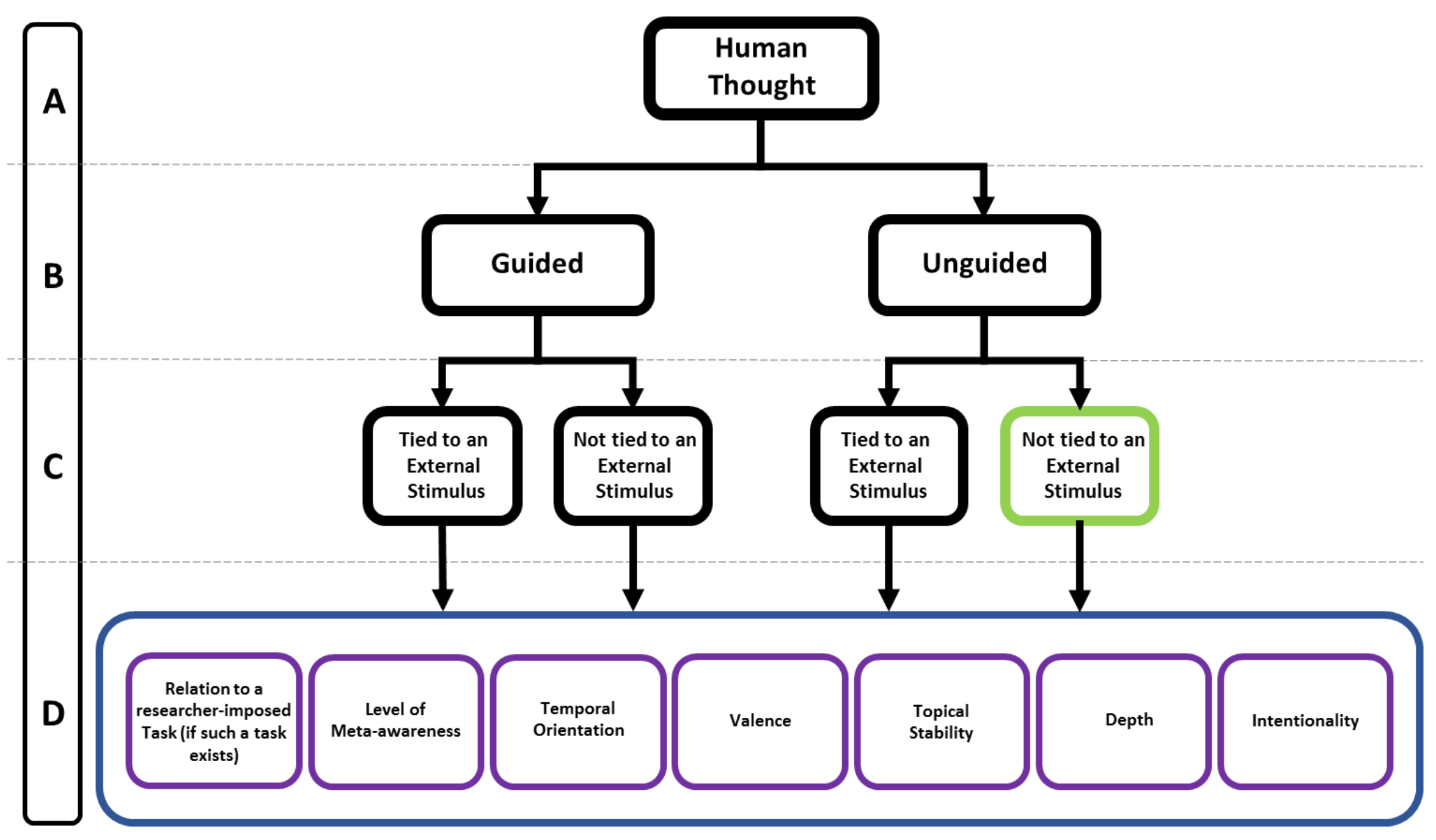

Figure 2. Hierarchical diagram depicting the relations of different categories of thought that must be considered in order to identify the prototypical case of mind wandering (Sections A, B, and C), as well as some of the many dimensions of mind wandering (Section D). Note: The green box denotes the prototypical case of mind wandering, which, by virtue of being unguided, is necessarily taskindependent thought. 